\title{
STRATEGI KOMUNIKASI BENCANA DALAM KESIAPAN MEMBANGUN MENTAL PEREMPUAN DALAM MENGHADAPI BENCANA KEBAKARAN PADA ANGGOTA PKK RW 06 KRANJI, PURWOKERTO TIMUR
}

\author{
Adita Miranti ${ }^{1)}$, Audito Anindya Bayu Aji ${ }^{2}$, Raja Satria Wibawa ${ }^{3)}$ \\ Universitas Amikom Purwokerto ${ }^{1)}$ \\ Universitas Amikom Purwokerto ${ }^{2)}$ \\ Universitas Amikom Purwokerto ${ }^{3)}$ \\ adita.miranti@amikompurwokerto.ac.id
}

\begin{abstract}
ABSTRAK
Banyaknya kejadian kebakaran di pemukiman penduduk yang disebabkan oleh kurangnya pemahaman tentang SOP dari penggunaan ala-alat rumah tangga dan menjadi dasar dilaksanakannya program pengabdian kepada masyarakat ini. Program ini berupa sosialisasi siaga bencana kebakaran ini bertujuan untuk memberikan pemahaman kepada ibu-ibu rumah tangga akan sadar betapa pentingnya keamanan dapur. Sosialiasi diadakan oleh dosen dan mahasiswa prodi Ilmu Komunikasi Universitas Amikom Purwokerto bekerja sama dengan Tim Purwokerto Rescue kepada anggota PKK RW 6 Kranji, Purwokerto Utara. Para peserta mendapatkan pelatihan cara mengatasi suatu khasus kebakaran yang terjadi dalam rumah tangga seperti cara mengatasi gas yang bocor akibat pemasangan regulator yang salah dan kebocoran selang gas. Kegiatan ini dapat menjadi sarana bagi ibu-ibu untuk mengetahui lebih jauh tentang pencegahan kebakaran di rumah dan sebagai sharing center. Oleh karena itu, kasus kebakaran dapat dikurangi dan diminimalisir dampaknya dengan adanya pengetahuan setiap individu dan masyarakat tentang kebakaran dan bagaimana cara mencegah, menghadapi dan menanggulangi adanya kebakaran melalui kegiatan sosialisasi ini.
\end{abstract}

Kata Kunci: Komunikasi Bencana, Sosialisasi, Perempuan

\begin{abstract}
The number of fires in residential areas is caused by a lack of understanding of SOPs from the use of household tools and is the basis for the implementation of this community service program. This program in the form of fire disaster preparedness socialization aims to provide housewives with an understanding of how important kitchen safety is. The socialization was held by lecturers and students of the Communication Science Study Program at Amikom Purwokerto University in collaboration with the Purwokerto Rescue Team to members of PKK RW 6 Kranji, North Purwokerto. The participants received training on how to deal with a typical household fire, such as how to deal with leaking gas due to incorrect installation of the regulator and leakage of gas hoses. This activity can be a means for mothers to find out more about fire prevention at home and as a sharing center. Therefore, fire cases can be reduced and their impact minimized by having knowledge of each individual and community about fires and how to prevent, deal with and cope with fires through this outreach activity.
\end{abstract}

Keywords: Disaster Communication, Socialization, Women

\section{PENDAHULUAN}

Bencana adalah peristiwa atau rangkaian peristiwa yang mengancam dan mengganggu kehidupan dan penghidupan masyarakat yang disebabkan, baik oleh faktor alam dan/atau nonalam maupun faktor manusia sehingga mengakibatkan timbulnya korban jiwa manusia, kerusakan lingkungan, kerugian harta benda, dan dampak psikologis (UU 24/2007)

Pengetahuan tentang siaga bencana penting ditanamkan kepada ibu-ibu saat ini. Salah satunya yaitu tentang strategi komunikasi bencana kebakaran. Dalam upaya mencegah atau meminimalkan potensi dampak bencana kebakaran pada masa mendatang diperlukan perencanaan program mitigasi 
dan kesiagaan terhadap bencana kebakaran.

Dalam penelitian ini peneliti menganalisa bahwa perempuan merupakan salah satu yang cukup rentan menjadi korban dari bencana salah satu nya bencana kebakaran. Penelitian ini mengangkat tema tentang strategi komunikasi bencana dalam kesiapan perempuan dalam menghadapi bencana kebakaran.

Berdasarkan data dari Badan Nasional Penanggulangan Bencana (BNBP) menyatakan bahwa perempuan memiliki risiko $\underline{14 \quad \text { kali }}$ lebih tinggi menjadi korban bencana dibanding pria dewasa. Hal ini disebabkan karena naluri perempuan yang ingin melindungi keluarga dan anak-anaknya, sehingga seringkali membuat mereka mengabaikan keselamatan diri sendiri.

Tingginya jumlah perempuan yang menjadi korban bencana alam disebabkan beberapa hal.

- Pertama, adanya konstruksi nilai dalam masyarakat yang mengharapkan perempuan untuk lebih dahulu menyelamatkan anggota keluarganya.

- Kedua, perempuan sering tidak dapat hadir dalam latihan penyelamatan diri dari kondisi bencana alam. Hal itu terjadi karena konstruksi nilai budaya di mana perempuan fokus pada urusan domestik sehingga jarang bisa keluar rumah untuk mengikuti pelatihan.

- Ketiga, ketidakhadiran perempuan dalam pendidikan bencana membuat pengetahuan mereka terkait pencegahan dan penanggulangan bencana menjadi minim. Pengetahuan yang terbatas soal teknik penyelamatan diri membawa konsekuensi perempuan lebih rentan menjadi korban bencana alam.

- Keempat, ada faktor kurangnya pengetahuan lokal dalam masyarakat tentang pengenalan gejala awal bencana alam. Dan perempuan sebagai kelompok dengan akses yang minim terhadap penyebaran pengetahuan menjadi rentan.

Tidak terkecuali perihal bencana kebakaran, perempuan rentan menjadi korban lantaran konstruksi secara gender yang dianggap bahwa secara mental perempuan memiliki mental yang tidak lebih kuat dari lakilaki, sehingga pengetahuan yang harus ditanamkan terutaman untuk mereka yang lebih banyak berada didalam rumah yaitu berkaitan dengan keberanian dalam memadamkan api jika terjadi kebakaran, serta pengetahuan untuk lebih memperhatikan keselamatan ketika berada di dapur. Salah satunya memeriksa keamanan alat-alat yang berpotensi menimbulkan kebakaran. Fungsi komunikasi dirasa sangat penting untuk memberikan informasi dan edukasi bagi masyarakat salah satunya kepada ibu-ibu rumah tangga.

Strategi komunikasi sangat penting dilakukan untuk mengubah paradigma masyarakat, khususnya kaum perempuan yang merasa takut untuk memadamkan api secara tradisional jika terjadi kebakaran.

Mayoritas dari mereka takut terhadap api dan cenderung panik jika adanya gangguan terhadap kompor, tanpa melakukan penanganan dan mitigasi bencana kebakaran. Dengan adanya sosialisasi ini, masyarakat diajak untuk tidak mudah panik apabila terjadi gangguan yang dapat memicu 
terjadi kebakaran ketika berada di dapur serta bisa menghadapinya dengan aman, tenang dan tentunya dengan mengutamakan keselamatan.

Sosialisasi tanggap bencana kebakaran ini bertujuan untuk memberikan pengetahuan serta pemahaman tentang langkah awal yang harus dilakukan jika terjadi kebakaran dan dapat membentuk mental ibu-ibu rumah tangga untuk tetap tenang jika terjadi permasalah yang berpotensi menimbulkan api ketika berada di rumah.

Tim Purwokerto Rescue sebagai pelatih memberikan pelatihan langsung seperti apa langkah awal yang dapat dilakukan apabila terjadi kebakaran dan tips merawat peralatan memasak seperti kompor dan gas.

Kebakaran adalah api yang tidak terkendali, yang berarti diluar kemampuan dan keinginan manusia. Api tidak terjadi begitu saja tetapi merupakan suatu proses kimiawi antara uap bahan bakar dengan oksigen dan bantuan panas. Teori ini dikenal sebagai segitiga api (fire triamgle) (repository.usu.ac.id). Menurut teori ini, kebakaran terjadi karena 3 faktor yang menjadi unsur api, yakni bahan bakar (fuel), sumber panas (heat), dan oksigen.kebakaran terjadi apabila ketiga unsur tersebut saling bereaksi satu dengan lainnya. Tanpa adanya salah satu unsur tersebut, api tidak akan menyala. Teori ini dikembangkan oleh W.H Haesseler (1974). Menurut beliau, kebakaran disebabkan oleh empat faktor, yaitu bahan bakar, bahan pengoksidasi, suhu dan reaksi beranai. Ke empat unsur ini disebut Bidang Empat Api atau istilah lainnya ialah The Tetahedron of Fire (Zaini, 1998)

Para peserta juga mendapatkan pengetahuan tentang penyebab kebakaran. Kebakaran disebabkan oleh berbagai faktor, secara umum dikelompokan sebagai berikut :

\section{- Faktor Manusia}

Manusia sebagai salah satu faktor penyebab kebakaran antara lain: manusia yang kurang peduli terhadap keselamatan dan bahaya kebakaran, menempatkan barang stau menyusun

barang yang mungkin terbakar tanpa menghiraukan norma-norma pencegahan kebakaran,

pemakaian tenaga listrik melebihi kapasitas yang telah ditentukan, kurang memiliki rasa tanggung jawab dan disiplin, dan adanya unsur-unsur kesengajaan.

\section{- Faktor Teknis}

Kebakaran juga dapat disebabkan oleh faktor teknis khususnya kondisi tidak aman dan membahayakan yang meliputi :

1. Proses fisik/mekanis

Faktor penting yang menjadi peranan dalam proses ini adalah timbulnya panas akibat kenaikan suhu atau timbulnya bunga api, misalnya pekerjaan perbaikan dengan menggunakan mesin las atau kondisi instalasi listrik yang sudah tua atau tidak memenuhi standar.

2. Proses kimia

Kebakaran dapat terjadi ketika pengangkatan bahan-bahan kimia berbahaya, penyimpanan dan penanganan tanpa memperhatikan petunjuk-petunjuk yang ada.

\section{- Faktor Alam}

Salah satu faktor penyebab adanya kebakaran dan peledakan akibat faktor alam adalah petirdan gunung meletus yang dapat menyebabkan kebakaran hutan yang luas dan juga perumahan-perumahan yang dilalui oleh lahar panas dan lain-lain (Anonim, 2010). Kegiatan ini juga mengajarkan bagaimana 
penanggulangan dan pencegahan bahaya kebakaran. Dalam upaya prosedur tanggap darurat secara besar meliputi rencana dalam menghadapi keadaan darurat, pendidikan dan latihan penanggulangan keadaan darurat. Pendidikan dan latihan penanggulangan keadaan darurat seperti proses evakuasi atau pemindahan dan penutupan (Jusuf, 1999).

\section{Sedangkan}

menurut

Suprapto, (1995) ketentuan dan persyaratan teknis dalam proteksi kebakaran pada bangunan meliputi :

- Melakukan pemeriksaan dan pengecekan kondisi dan keadaan sarana dan peralatan sistem proteksi kebakaran

- Melengkapi sarana dan peralatan proteksi didasari atas analisis resiko bahaya dan standar serta ketentuan yang berlaku

- Standar serta ketentuan teknis proteksi kebakaran harus diterapkan dan disebarluaskan

- Setiap gerbang harus dilengkapi dengan sarana pengamanan terhadap kebakaran secara lengkap dan memenuhi standar dan ketentuan teknis yang berlaku

- Perlu dilakukan pemeriksaan dan pemeliharaan secara berkala untuk menjamin agar sarana dan peralatan proteksi kebakaran dalam kondisi siap pakai.

Pencegahan dan penanganan secara umum agar tidak terjadi kebakaran :

- Jangan mengisi minyak pada waktu kompor menyala

- Sumbu kompor jangan ada yang kosong

- Jangan meninggalkan kompor yang sedang menyala

- Jangan disiram dengan air, jangan diangkat, ditendang atau / tindakan lain yang dapat mengakibatkan kompor terguling

- Gunakan karung basah / sejenisnya untuk menutup kebakaran tersebut

- Gunakan Alat Pemadam Api Ringan ( APAR )

Ibu-ibu dilatih dan diajarkan bagaimana cara memasang regulator dan selang kompor agar benar-benar rapat dan perawatan kompor agar tetap terjaga kebersihannya. Juga dilatih cara menangani apabila terjadi kebocoroan pada gas, sehingga tidak sampai terjadi kebakaran besar. Melalui sosialisasi ini, diharapkan ibu-ibu bisa teratur dan tertib terhadap keamanan dapur. Kegiatan ini dapat menjadi sarana bagi ibu-ibu untuk mengetahui lebih jauh tentang pencegahan kebakaran di rumah dan sebagai sharing center. Oleh karena itu, kasus kebakaran dapat dikurangi dan diminimalisir dampaknya dengan adanya pengetahuan setiap individu dan masyarakat tentang kebakaran dan bagaimana cara mencegah, menghadapi dan menanggulangi adanya kebakaran melalui kegiatan sosialisasi ini.

\section{Masalah}

Berdasarkan observasi dan wawancara dosen sebagai fasilitator dengan Ketua PKK RW 6 Kranji, ditemukan (2) dua permasalahan yang dihadapi ibu-ibu peserta pelatihan. Pertama, kuranganya pemahaman ibuibu tentang SOP keamanan dapur. Kedua, kurangnya pengetahuan bagaimana cara mengatasi kebakaran yang biasa terjadi di dalam rumah atau dapur. 


\section{METODOLOGI PELAKSANAAN}

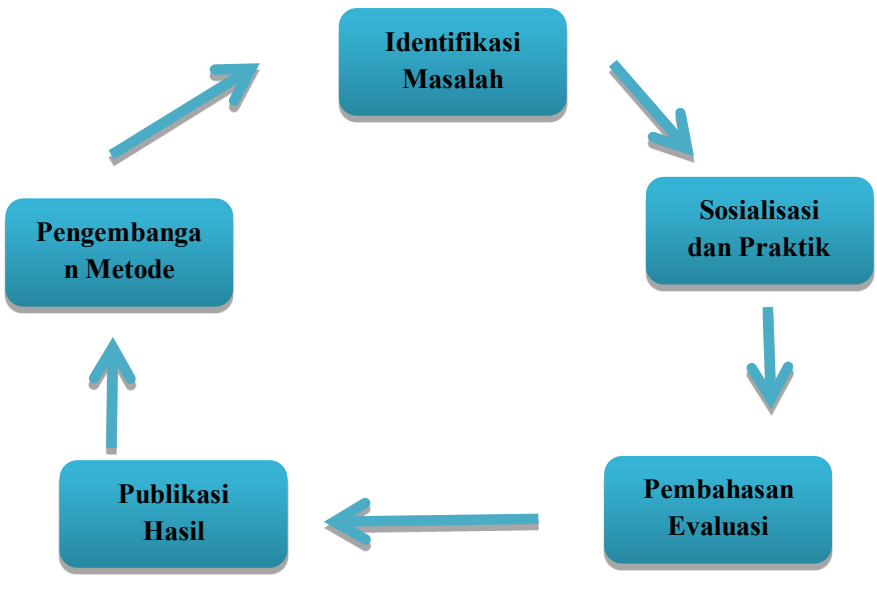

Pelaksanaan sosialisasi dilakukan dengan mengutamakan pemahaman ibu-ibu PKK di Purwokerto Timur terhadap konsep terjadinya kebakaran dan cara penanggulangannya. Sosialisasi didukung dengan metode penyampaian materi dan diskusi yang menarik dan mudah dipahami oleh peserta. Kemudian dilanjutkan dengan praktik pemadaman api dengan menggunakan handuk basah dan Alat Pemadam Api Ringan (APAR) dengan pengawasan. Evaluasi pemahaman terhadap sosialisasi dilakukan dengan diskusi lisan dan didukung dengan pemberian reward / hadiah.

\section{HASIL DAN PEMBAHASAN}

Pelaksanaan sosialisasi siaga bencana kebakaran yang dilakukan untuk melatih mental ibu-ibu rumah tangga khususnya anggota PKK di Purwokerto Timur yang pada umumnya takut untuk memadamkan api secara tradisional ketika terjadi kebakaran. Sosialisasi yang berlangsung sebanyak dua kali pertemuan ini berjalan dengan lancar dan memberikan efek yang bermanfaat bagi anggota PKK di Purwokerto Timur. Pelatihan dilaksanakan sebanyak dua kali dalam satu bulan dan dalam suasana santai namun serius agar para peserta dapat memahami materi pelatihan dengan baik dan berdampak positif bagi mental peserta dalam melatih keberanian jika terjadi. Pelatihan terlaksana dengan efektif. Hal tersebut dibuktikan dengan tingginya partisipasi dan antusiasme ibu-ibu dalam mengikuti serta mempraktekkan materi yang diberikan pada kegiatan ini.

Sesi pertama diawali dengan pengenalan dari fasilitator terkait materi yang akan disampaikan. Kemudian fasilitator melakukan sosialisasi dan praktek terkait pemahaman pentingnya pencegahan dan penanganan jika terjadi kebakaran.

Ibu rumah tangga menjadi sasaran sosialisasi dari praktek pemberdayaan perempuan dalam kesiapan menghadapi bencana salah satunya pada bencana kebakaran. Sebagai ibu rumah tangga yang banyak menghabiskan waktunya di dalam rumah, perempuan rentan menjadi korban karena dapat menjadi pemicu sekaligus pencegah kebakaran. Peran aktif kader PKK dalam pencegahan dan penanggulangan kebakaran diperlukan karena Kader PKK merupakan salah satu potensi masyarakat yang tugasnya kerap bersentuhan dengan warga. Dalam kegiatan tersebut salah satu praktek yang dilakukan adalah pemadaman kebakaran api dari kompor gas yang terbakar dengan menggunakan handuk basah dan APAR.

Para peserta yang mayoritas adalah perempuan awalnya merasa takut jika bersentuhan langsung dengan api dan tanpa memperhatikan SOP keamanan dapur. Melalui pelatihan tersebut, dapat merangsang keberanian para peserta untung 
memadamkan api secara langsung jika terjadi kebakaran.

Tim Purwokerto Rescue memberikan beberapa tips penting dalam mengatasi suatu kasus kebakaran yang terjadi dalam rumah tangga seperti, cara menangani gas yang bocor akibat pemasangan regulator yang salah, lalu juga cara memadamkan api akibat bahan bakar seperti minyak tanah, spirtus, bensin dan yang terkahir adalah cara mengatasi kebakaran yang di sebabkan oleh minyak goreng yaitu hal yang sering terjadi di dalam proses masak memasak. Ibu-ibu yang hadir juga diberi kesempatan untuk mencoba untuk lebih tau dan memahai cara mengatasi kebakaran yang biasa terjadi di dalam rumah atau dapur. Ibu-ibu RT 3 dan 4 merasa terbantu dengan adanya kegiatan sosisalisasi ini sebagai pengetahuan dan pemahaman mereka, agar nantinya bisa tanggap dan sigap apabila terjadi hal-hal yang tidak diinginkan.

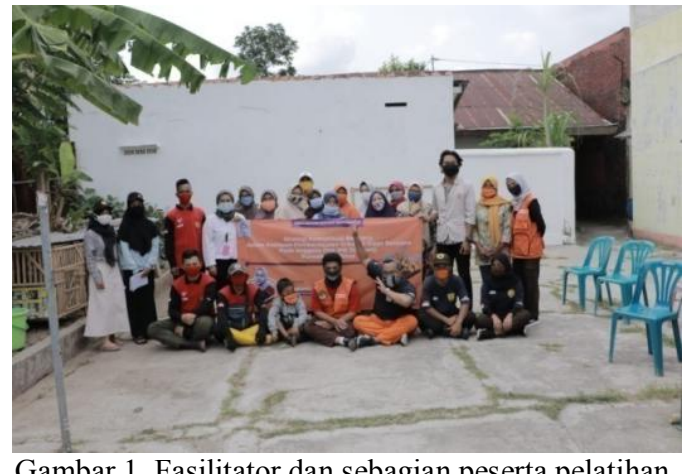

\section{KESIMPULAN}

Kegiatan PKM dalam bentuk sosialisasi siaga tanggap bencana yang diselenggarakan oleh dosen prodi Ilmu Komunikasi Universitas Amikom Purwokerto bersama Tim Purwokerto Rescue berjalan efektif. Pemahaman dan pengetahuan ibu-ibu sebagai peserta sosialisasi semakin meningkat.
Para peserta mengikuti sosialisasi dengan serius dan antusias.

Setelah mengikuti pelatihan, diharapkan para peserta yang mayoritas perempuan awalnya merasa takut jika bersentuhan langsung dengan api dan tanpa memperhatikan SOP keamanan dapur. Melalui pelatihan tersebut, dapat merangsang keberanian para peserta untung memadamkan api secara langsung jika terjadi kebakaran

Berdasarkan capaian yang diperoleh, diharapkan dapat dilakukan secara berkesinambungan untuk mendapatkan hasil yang optimal. Dan diharapkan peserta sosialisasi dapat memahami materi dan persoalan kebakaran dan menambah wawasan pengetahuan mengenai kebakaran dan bagaimana upaya untuk menanggulangi dan mencegah kebakaran sehingga kasus kebakaran dapat diminimalisir.

\section{UCAPAN TERIMAKASIH}

Penulis

mengucapkan terimakasih kepada Universitas Amikom Purwokerto atas pendanaan dan dukungannya dalam pelaksanaan Pengabdian Kepada Masyarakat ini.

\section{REFERENSI}

Aditiansyah, I., (2014). Hubungan antara Tingkat Pengetahuan Penghuni dan Fasilitas Rumah Susun Terhadap Kesiapan Tanggap Darurat Bencana Kebakaran di Rumah Susun Pekunden Kota Semarang. Skripsi. Semarang: Universitas Dian Nuswantoro.

Alzahra, V., Widjasena, B. \& S., (2016). Analisis Mitigasi Non Struktural Kebakaran dalam Upaya Pencegahan Bencana Kebakaran di Gedung Bertingkat 
Perkantoran X Jakarta. Jurnal Kesehatan Masyarakat, Volume 4, pp. 2356-3346.

Ramli, S., (2010). In: Pedoman Praktis Manajemen Bencana. Jakarta: Dian Rakyat.
Zaini, Mochammad. (1998). Panduan Pencegahan dan Pemadaman Kebakaran. Jakarta: Abdi Tandur 